\title{
Immunoreactivity for alpha-smooth muscle actin characterizes a potentially aggressive subgroup of little basal cell carcinomas
}

\author{
L. Pilloni, ${ }^{1}$ P. Bianco, ${ }^{1}$ C. Manieli, ${ }^{1}$ G. Senes, ${ }^{1}$ P. Coni, ${ }^{1}$ L. Atzori, ${ }^{2}$ N. Aste, ${ }^{2}$ G. Faa ${ }^{1}$ \\ ${ }^{1}$ Dipartimento di Citomorfologia, I Cattedra di Anatomia Patologica; ${ }^{2} \mathrm{Clinica}$ Dermatologica Università \\ degli studi di Cagliari, Italy
}

(C2009 European Journal of Histochemistry

Basal cell carcinoma (BCC) is a very common malignant skin tumor that rarely metastatizes, but is often locally aggressive. Several factors, like large size (more than $3 \mathrm{~cm}$ ), exposure to ultraviolet rays, histological variants, level of infiltration and perineural or perivascular invasion, are associated with a more aggressive clinical course. These morphological features seem to be more determinant in mideface localized BCC, which frequently show a significantly higher recurrence rate. An immunohistochemical profile, characterized by reactivity of tumor cells for p53, Ki67 and alpha-SMA has been associated with a more aggressive behaviour in large BCCs. The aim of this study was to verify if also little $(<3 \mathrm{~cm})$ basal cell carcinomas can express immunohistochemical markers typical for an aggressive behaviour.

Correspondence: Pilloni Luca,

Ricercatore confermato, Dipartimento di Citomorfologia, I Cattedra di Anatomia Patologica,

Università degli Studi di Cagliari, Italy

Tel.: +39.070.6092424.

Fax: +39.070.6092370.

E-mail: lucpilloni@tiscali.it

Paper accepted on 29 May 2009

European Journal of Histochemistry

2009; vol. 53 issue 2 (April-June): 113-116
B asal cell carcinoma ( $B C C$ ) is a very common malignant skin tumor that rarely metastatizes, even if is often locally aggressive. Several factors, like large size (more than $3 \mathrm{~cm}$ ), face localization, exposure to ultraviolet rays, histological variants, infiltration level and perineural or perivascular invasion, are associated with a more aggressive clinical course. In particular, the incidence of metastasis and/or death correlates with tumors greater than $3 \mathrm{~cm}$ in diameter in which setting patients are said to have $1-2 \%$ risk of metastases that increases to $20-25 \%$ in lesions greater than $5 \mathrm{~cm}$ and to $50 \%$ in lesions greater than 10 $\mathrm{cm}$ in diameter (Snow et al., 1994). Histologically morpheiform, keratotic types and infiltrative growth of BCC are also considered features of the most aggressive course (Crowson, 2006). This can be explained by the fact that both the superficial and nodular variants of BCC are surrounded by a continuous basement membrane zone comprising collagens type IV and V admixed with laminin, while the aggressive growth variants (i.e. morpheiform, metatypical, and infiltrative growth subtypes) manifest the absence of basement membrane (Barsky et al., 1987).

The molecular markers which characterize aggressive BCC include: increased expression of stromolysin (MMP-3) and collagenase-1 (MMP-1) (Cribier et al., 2001), decreased expression of syndecan-1 proteoglycan (Bayer-Garner et al., 2000) and of anti-apoptotic protein bcl-2 (Ramdial et al., 2000; Staibano et al., 2001).

C-ras, c-fos (Urabe et al., 1994; Van der Schroeff et al., 1990) and p53 tumor supressor gene mutations (Auepemikiate et al., 2002) are indicative of an aggressive course.

Focusing upon bcl-2 and p53 expression in BCC, there have been numerous studies documenting the utility of bcl-2 as a marker of favourable clinical behaviour while 053 expression may be a feature of a more aggressive outcome (Ramdial et al., 2000; Staibano et al., 2001; Bozdogan et al., 2002). 
Table 1. Clinical (age, sex, location, size), histological (histotype, depth infiltration in millimetre, ulceration, essudation and level of infiltration according anatomical skin layers URD upper reticular dermis; DRD deep reticular dermis ) and immunohistochemical data of 31 cases of BBC; essudation Mild=+; Moderate=++;Severe=+++; immunohistochemical score: 0= 0-6\%; 1= 6-25\%; 2= 25-50\%; $3=51-75 \% ; 4=76-100 \%$.

\begin{tabular}{|c|c|c|c|c|c|c|c|c|c|c|c|c|c|}
\hline & Age & Sex & Location & Hystotype & Max.Dim & Depth & Ulc & Ess & $\operatorname{lnf}$ & p53 & $B c l-2$ & Ki67 & $A M L$ \\
\hline 1 & 61 & $M$ & Extr & Keratotic & $10 \times 8$ & 1 & No & +++ & URD & +++ & + & + & - \\
\hline 2 & 61 & $M$ & Face & Adenoid & $10 \times 9$ & 4 & No & + & URD & +++ & - & - & - \\
\hline 3 & 64 & $M$ & Extr & Sup mult & $11 \times 13$ & 0.8 & No & + & DRD & + & - & - & - \\
\hline 4 & 73 & M & Face & Nodular & 10x8 & 2 & Yes & + & DRD & +++ & + & ++ & +++ \\
\hline 5 & 84 & M & Face & Nodular & $9 \times 12$ & 2 & Yes & + & DRD & - & - & - & - \\
\hline 6 & 84 & $M$ & Face & Adenoid & 5 & 0.8 & No & + & URD & +++ & - & - & - \\
\hline 7 & 84 & $M$ & Extr & Nodular & $13 \times 10$ & 3 & No & + & DRD & +++ & + & + & - \\
\hline 8 & 52 & $\mathrm{~F}$ & Face & Nodular & 4 & 0.8 & No & + & URD & + & + & + & - \\
\hline 9 & 76 & $\mathrm{~F}$ & Face & Adenoid & $10 \times 4$ & 4 & No & + & DRD & +++ & - & ++ & - \\
\hline 10 & 77 & $\mathrm{~F}$ & Face & Morph & $8 \times 6$ & 1 & Yes & +++ & DRD & +++ & - & - & - \\
\hline 11 & 86 & M & Face & Morph & 8 & 1 & Yes & + & DRD & +++ & - & + & + \\
\hline 12 & 63 & $\mathrm{~F}$ & Face & Adenoid & 4 & 1 & No & + & URD & ++ & + & + & + \\
\hline 13 & 76 & $\mathrm{~F}$ & Face & Nodular & 7 & 1.5 & No & + & DRD & +++ & + & ++ & - \\
\hline 14 & 84 & $M$ & Face & Nodular & 11 & 4 & Yes & +++ & DRD & + & - & - & + \\
\hline 15 & 63 & $\mathrm{~F}$ & Face & Keratotic & $10 \times 6$ & 1.8 & No & ++ & DRD & - & + & ++ & - \\
\hline 16 & 68 & $\mathrm{~F}$ & Trunk & Sup mult & $10 \times 6$ & 0.7 & No & ++ & URD & + & + & - & - \\
\hline 17 & 67 & M & Face & Sup mult & $12 \times 6$ & 0.4 & No & + & URD & + & - & + & - \\
\hline 18 & 67 & $M$ & Extr & Sup mult & $4 \times 3$ & 0.3 & No & + & URD & + & +++ & + & - \\
\hline 19 & 32 & $\mathrm{~F}$ & Extr & Sup mult & $1 \times 3$ & 0.4 & No & + & URD & + & + & + & - \\
\hline 20 & 45 & M & Trunk & Nodular & $7 \times 5$ & 2 & Yes & +++ & URD & + & + & + & - \\
\hline 21 & 62 & $M$ & Trunk & Sup mult & $11 \times 7$ & 0.9 & No & ++ & URD & - & ++ & - & ++ \\
\hline 22 & 65 & M & Trunk & Adenoid & $7 \times 6$ & 1.5 & No & + & URD & +++ & + & + & - \\
\hline 23 & 72 & M & Trunk & Nodular & $12 \times 6$ & 1 & No & + & URD & +++ & - & + & + \\
\hline 24 & 86 & $\mathrm{~F}$ & Face & Keratotic & $20 \times 11$ & 3.1 & No & ++ & DRD & + & + & + & - \\
\hline 25 & 85 & $M$ & Face & Nodular & 0.5 & 1.3 & No & ++ & DRD & ++ & + & + & - \\
\hline 26 & 74 & $\mathrm{~F}$ & Extr & Nodular & $4 \times 4$ & 0.9 & No & + & URD & - & - & + & - \\
\hline 27 & 71 & M & Face & Nodular & $6 \times 12$ & 1.7 & No & + & DRD & - & - & + & - \\
\hline 28 & 64 & $\mathrm{~F}$ & Trunk & Sup mult & $1.3 \times 1.5$ & 0.4 & No & ++ & URD & +++ & - & - & - \\
\hline 29 & 78 & $\mathrm{~F}$ & Face & Nodular & $4 \times 3$ & 1.5 & No & ++ & DRD & ++ & + & - & +++ \\
\hline 30 & 80 & M & Face & Keratotic & $4 \times 4$ & 1.6 & Yes & + & DRD & - & - & + & +++ \\
\hline
\end{tabular}

Table 2. Comparison of our $8 \alpha$-SMA positive cases with negative cases.

\begin{tabular}{|c|c|c|c|c|c|c|c|c|c|}
\hline & \multirow{2}{*}{$\frac{\text { Location }}{\text { Face }}$} & \multicolumn{2}{|c|}{ Histotype } & \multicolumn{3}{|c|}{ Local aggressiveness } & \multicolumn{3}{|c|}{ Immunohistochemistry } \\
\hline & & Keratotic & Morpheiform & $\begin{array}{l}\text { Depht of invasion } \\
\text { Mean value }(\mathrm{mm})\end{array}$ & Ulceration & $\begin{array}{l}\text { Infiltration } \\
\text { of the dermis }\end{array}$ & P53 & $B C l-2$ & Ki67 \\
\hline $\begin{array}{l}8 \alpha \text {-SMA } \\
\text { positive cases }\end{array}$ & $75 \%$ & $12 \%$ & $12 \%$ & 1.6 & $50 \%$ & $63 \%$ & $75 \%$ & $50 \%$ & $63 \%$ \\
\hline $\begin{array}{l}23 \alpha \text {-SMA } \\
\text { negative cases }\end{array}$ & $56 \%$ & $13 \%$ & $4 \%$ & 1.4 & $13 \%$ & $48 \%$ & $78 \%$ & $43 \%$ & $65 \%$ \\
\hline
\end{tabular}

An increased expression of cytoskeletal microfilaments like $\alpha$-smooth muscle actin, frequently found in invasive BCC subtypes (Jones JCR et al., 1989), may explain an enhanced tumor mobility and deep tissue invasion through the stroma. (Cristian et al., 2001; Law et al., 2003). The aim of this preliminary study was to verify if also little $(<3 \mathrm{~cm})$ basal cell carcinomas may express aggressive immunohistochemical markers like p53, Ki67 and alphaSMA. We used 31 excisional BCCs with tumor size less than $2 \mathrm{~cm}$ (ranging from 2 up to $20 \mathrm{~mm}$ ) and with different skin localization (19 in the face, 6 in the trunk and 6 in the body extremities). All cases were immunostained for p53, BCL2, Ki67 and alpha-smooth muscle actin ( $\alpha$-SMA) (Table 1 ). Immunoreactivity was evaluated by a semiquantitative score from 0 to 4 , and interpreted by a two board-certified dermatopathologists (L.P. and C.M).

Our data show that p53 (75\%), Bcl2 (50\%) and Ki67 (63\%) positivity was generally diffuse in the majority of cases. On the contrary, cytoplasmatic $\alpha$ - 
SMA expression was present only in 8 out of 31 cases $(25,8 \%)$. All these $8 \alpha$-SMA positive BCCs, prevalently found in the mideface (6 out of 8 ), were characterized by an initial invasion beyond the dermis. Among these 6 face-localized $\alpha$-SMA positive BCCs, 1 showed a sclerosing aggressive histotype, 1 a keratotic type and 4 a nodular histotype.

These 8 little $\alpha$-SMA-positive BCCs, compared to the others $23 \alpha$-SMA negative samples, all showed a major aggressiveness features: facial location, ulceration, morpheiform histotype and deeper infiltration into the dermis (Table 2). In particular, $75 \%$ of these $\alpha$-SMA positive BCCs were localized in the midface; $24 \%$ presented with an aggressive histotype (keratotic and morpheiform); 50\% showed ulceration; $63 \%$ tended to infiltrate the dermis deeply, with a mean depth of invasion of 1,6 $\mathrm{mm}$ (Table 2).

Given the absence of a specific difference between $\alpha$-SMA positive cases and $\alpha$-SMA negative cases in the expression of aggressive immunohistochemical markers, except for a light reduction of bcl-2 in the $\alpha$-SMA positive group (Table 2), we focused our attention not only on the single marker but on the several possible immunohistochemical profiles that we could obtain (Tables 1 and 2). By the analysis of the data, we selected the combination that could better define an aggressive behaviour even for little BCC: $\alpha$-SMA, p53, Ki67 positivity and bcl-2 negativity. We considered p53 and ki67 markers of proliferation and cell-cycle alteration, combined with a loss of apoptotic activity expressed by Bcl-2 negativity, quite characteristic of aggressiveness; moreover $\alpha$-SMA positivity probably reflects invasive potential and acquired mobility by neoplastic cells.

This immunohistochemical profile ( $\alpha-S M A, p 53$, Ki67 positivity and bcl-2 negativity) in our cases of $\mathrm{BCC}$ is present in two of them; one is a morpheiform BCC, that is an aggressive variant, while the other one is a nodular subtype (less aggressive).

Therefore, our preliminary data suggest that only $\alpha$-SMA positivity should be considered as an early diagnostic marker of potential aggressiveness in little BCC: all $\alpha$-SMA positive little BCC in fact showed clinical and histological features of aggressiveness. Invasive potential is probably acquired by some BCCs not only when they reach large size, but it is probably present also when they have still little size, and can be revealed by $\alpha$-SMA positivity in the neoplastic cells.

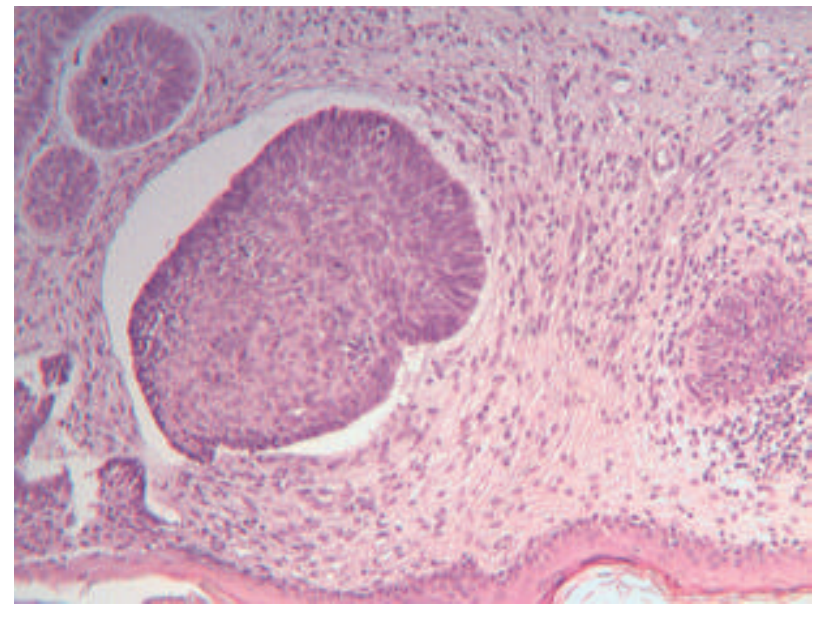

Figure 1. BCC, nodular type, HE, 10x.

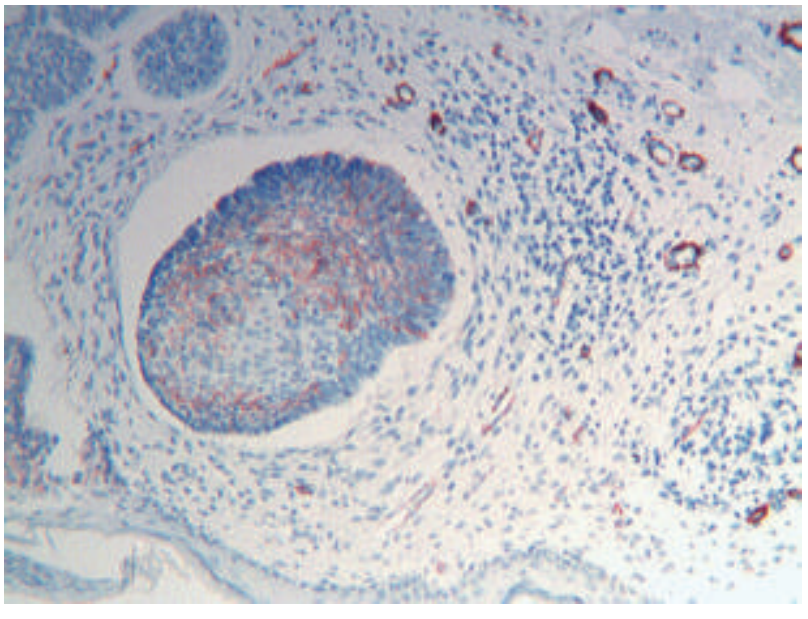

Figure 2. BCC, nodular type, $\alpha$-SMA positivity, 10x.

\section{References}

Auepemikiate $S$, Boonyaphiphat $P$, Thongsuksai P. p53 expression to relate to the aggressive infiltrative histopathologic features of basal cell carcinoma. Histopathol 2002;40:568-73.

Barsky SH, Grossmann DA, Bhuta S. Desmoplastic basal cell carcinoma possess unique basement membrane-degrading properties. J Invest Dermatol 1987;88:324-9.

Bayer-Garner I, Dilday B, Sanderson ND, Smoller BR. Syndecan-1 expression is decreased with increasing aggressiveness of basal cell carcinoma. Am J Dermatopathol 2000;22:119-22.

Bozdogan 0, Erkek E, Atasoy P, Koçak M, Birol A, Caydere M. Bcl-2related proteins, alpha-smooth muscle actin and amyloid deposits in aggressive and non-aggressive basal cell carcinomas. Acta Derm Venereol 2002;82:423-7.

Cribier B, Noacco G Peltre B, Grosshans E. Expression of stromelysin 3 in basal cell carcinomas. European J Dermatol 2001;11:530-3.

Cristian M, Moy RL, Wagner RF, Yen-Moore A. A correlation of alphasmooth muscle actin an invasion in micronodular basal cell carcinoma. Dermatol Surg 2001;27:441-5

Crowson AN. Basal cell carcinoma: biology, morphology and clinical implications. Modern Pathology 2006; 19:S127-47.

Hobart W.Walling, Fosko SW, Geraminejad PA, Whitaker DC, Arpey CJ. Aggressive basal cell carcinoma: Presentation, pathogenesis and management. Cancer and Metastasis Reviews 2004; 23:389-402.

Jones JCR, Steinman HK, Goldsmith BA. Hemidesmosomes, collagen VII and intermediate filaments in basal cell carcinoma. J Invest. 
L. Pilloni et al.

Dermatol 1989; 93:662-71.

Law AM, Oliveri CV, Pacheco-Quinto X, Horenstein MG. Actin expression in purely nodular versus nodular-infiltrative basal cell carcinoma. J Cutan Pathol. 2003; 30: 232-6.

Ramdial P, Madaree A, Reddy R, Chetty R. bcl-2 protein expression in aggressive and in non aggressive carcinomas. J Cutaneous Pathol 2000; 27: 283-91.

Snow SN, Sahl WJ, Lo JS, Mohs FE, Warner T, Dekkinga JA, Feyzi J. Metastatic basal cell carcinoma: report 5 cases. Cancer $1994 ; 73: 328-35$
Staibano S, Lo Muzio L, Pannone G, Scalvenzi M, Salvatore G, Errico ME, Fanali S, De Rosa G, Piatelli A. Interaction between bcl-2 and p53 in neoplastic progression of basal cell carcinoma of the head and neck. Anticancer Research 2001; 21:3757-64.

Urabe A, Nakayama J, Tani Guchi S, Kuroki R, Hori Y. Expression of the fos oncogene in basal cell carcinoma. J Dermatol Sci 1994; 8:50-3.

Van der Schroeff J, Evers LM, Boot AJM, Bos JL. Ras oncogene point mutation in basal cell carcinomas and squamous cell carcinomas of the human skin. J Invest Dermatol 1990; 94:423-25. 